\title{
49 DAYLIGHT MEASUREMENT IN INDONESIA
}

\section{Part 1. Outline, of the measurement}

\section{Ramli RAHIM, Hiroshi NAKAMURA, Yasuko KOGA, Koichi GOTO (KYUSHU UNIVERSITY)}

\section{INTRODUCTION}

Many proposals have been made by various research workers in the world for the prediction and design of daylight and solar radiation environment in interior. However, all fundamental materials for those proposals are based upon the measured data at the areas of high latitude were the solar altitude rather low. So they can not be applied in low latitude area where the solar altitude often becomes very high.

In order to take data from low latitude area where the sun reaches the zenith or near the zenith, a measurement of daylight and solar radiation was done in Ujung Pandang, Indonesia from May 4th to November 13rd, 1992 (188 days). The outline of the measurement is mainly introduced in this paper.

\section{LOCATION OF MEASUREMENT STATION}

The station data gathered is located in Campus of Hasanuddin University, Tamalanrea, Ujung Pandang $\left(05^{\circ} 04^{\prime} \mathrm{S}, 119^{\circ} 33^{\prime} \mathrm{E}\right)$. All the measurement instruments (sensors) have been set on a measurement plan $(80 \times 80 \mathrm{~cm})$ of a measuring tower which had constructed at the flat roof of the building of the Hasanuddin University Central Workshop. The flat roof of the building is $17.70 \mathrm{~m}$ above the sea level and the top of the measuring tower is $23.70 \mathrm{~m}$, as the height of the flat roof from the ground level is $9.20 \mathrm{~m}$ and the height of the measuring tower is $6.00 \mathrm{~m}$ (the ground level is $8.50 \mathrm{~m}$ above the sea level). There are no obstructions above the horizon around the measuring tower which shade the measuring instruments; a lightning rod attached on the top of the main roof $(14.00 \mathrm{~m}$ distance from the measuring tower), however, is negligible. Fig. 1 shows the measuring tower and the building of Central Workshop.

\section{MEASUREMENT ITEMS}

Five items are measured, that is, Global illuminance (Evg), Diffuse illuminance (Evd), Global irradiance (Eeg), Diffuse irradiance (Eed) and Zenith luminance (Lvz). The station instrumentation consist of two illuminance sensors (illuminometers), two irradiance sensors (pyranometers) that measure global and diffuse components and one zenith luminance sensor (luminance meter). For both diffuse illuminance and diffuse irradiance measurements, the sun is blocked by a shadow ring.

Table 1 shows the measurement items and the instruments with their specification.

\section{DATA ACQUISITION, STORAGE AND PROCESSING}

The daylight and solar radiation data are gained at every one-minute intervals continuously for twenty-four hours by instruments and transferred to a personal computer (EPSON PC-286LS) via amplifier. All of them are displayed on Visual Display Unit (VDU) as a table and a graphical diagram. They are stored instantaneously in a 3.5"-1.2 MB floppy diskette which can hold raw data of a little more than 12 days on drive $A$ as well as micro computer program. The raw data in drive $A$ is transferred automatically into drive B every midnight which can stored data of a little more than three weeks.

All of the instruments are checked three times a day in order to keep their working correct and all of their conditions are note down in a log book, including the weather conditions. The data from the floppy diskette in drive $B$ are going to be processed and arranged for analyzing after checked by quality controls [1]. Fig. 2 shows the measurement system. 


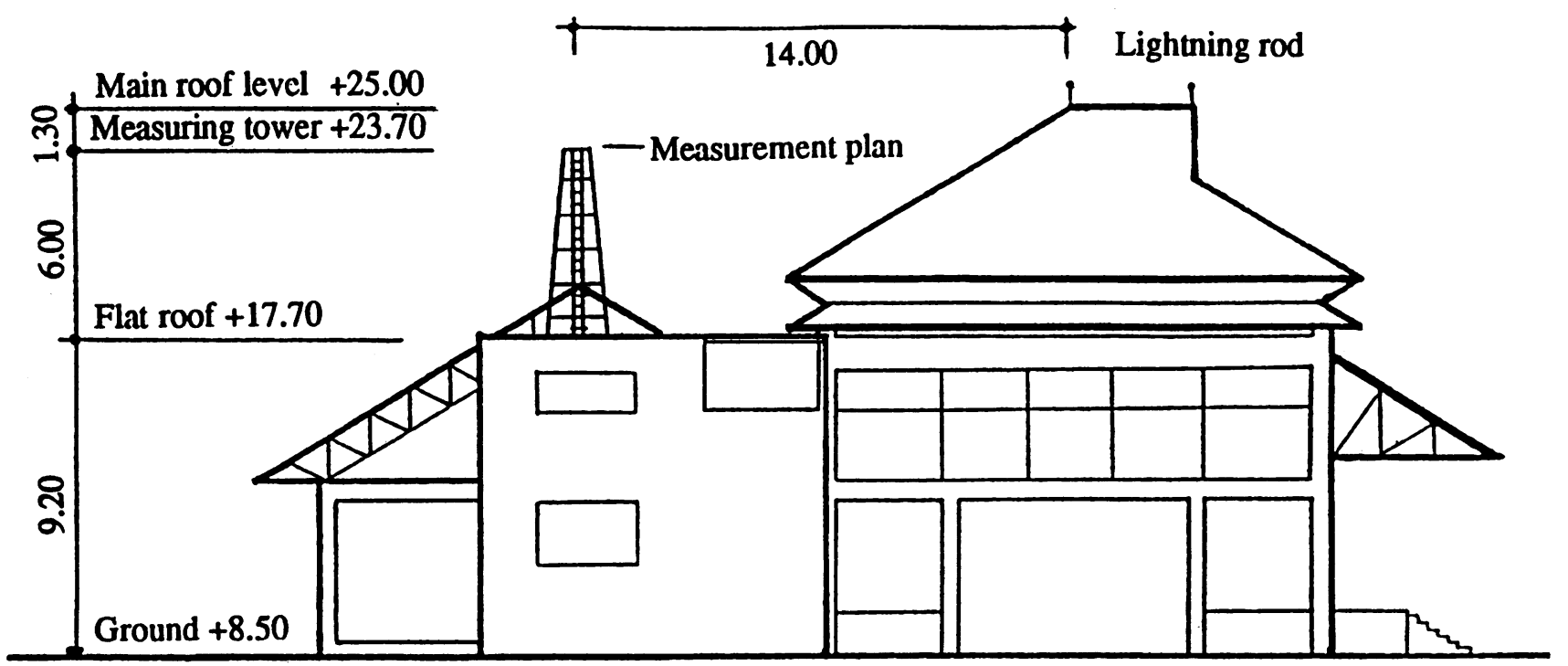

Fig. 1 Measuring tower (East view)

\section{CONCLUSION}

The data gained this time is considered to be not so reliable by the authors, because they are effected by unexpected noise. The measurement instruments are simplified as possible, because they should be carried from Japan.

However, the measured data of daylight and solar radiation in Ujung Pandang, Indonesia as one point in low latitude area will surely produce useful material on daylight and solar radiation soon in order to extend their applicable until solar altitude $90^{\circ}$ conditions.

\section{ACKNOWLEDGMENT}

The authors want to express sincere thanks to Prof. Dr. Basri Hasanuddin M.A. (Rector of Hasanuddin University), Prof. Dr. Ir. Arifuddin Ressang (Dean of Faculty of Engineering, Hasanuddin University), Ir. $\mathrm{H}$. Maruddin Laining, MS. (Director of Hasanuddin University Central Workshop) for their kind cooperation and warm assistance.

\section{REFERENCE}

1. CIE TC-3.07 : "Guide to Recommended Practice of Daylight Measurement", CIE TC3.07 Seventh Draft, June 1991.
Table 1

Measurement items, instruments and specification

\begin{tabular}{|c|c|c|}
\hline $\begin{array}{l}\text { Measurement Items } \\
\text { (Instruments) }\end{array}$ & Range & Specification \\
\hline Global illuminance & $0-200$ & d:12.4mm a:5\% \\
\hline Diffuse illuminance & $0-200$ & $\mathrm{~d}: 12.4 \mathrm{~mm}$ a: $5 \% \mathrm{w}: 50 \mathrm{~mm}$ \\
\hline (Illuminometer + ring) & & $\mathrm{r}: 125 \mathrm{~mm} \quad \mathrm{w} / \mathrm{r}: 0.4$ \\
\hline $\begin{array}{l}\text { Global irradiance } \\
\text { (Pyranometer) }\end{array}$ & $\begin{array}{l}0-1.4 \\
\mathrm{~kW} / \mathrm{m}^{2}\end{array}$ & $\mathrm{~d}: 11 \mathrm{~mm} \quad \mathrm{a}: 1.5 \%$ \\
\hline Diffuse irradiance & $0-1.4$ & $\mathrm{~d}: 11 \mathrm{~mm}$ a: $1.5 \% \mathrm{w}: 50 \mathrm{~mm}$ \\
\hline (Pyranometer + ring) & $\mathrm{kW} / \mathrm{m}^{2}$ & $\mathrm{r}: 125 \mathrm{~mm}$ w/r:0.4 \\
\hline $\begin{array}{l}\text { Zenith luminance } \\
\text { (Luminance meter) }\end{array}$ & $\begin{array}{l}0-55 \\
\mathrm{kcd} / \mathrm{m}^{2}\end{array}$ & $\begin{array}{l}\text { d: } 11 \mathrm{~mm} \text { a: } 1.5 \% \\
\text { h:5.5 }\end{array}$ \\
\hline $\begin{array}{l}\text { d:diameter of the sensor } \\
\text { a:accuracy } \\
\text { h:half-aperture angle }\end{array}$ & & $\begin{array}{l}\text { w:width of the band } \\
\text { r:radius of the shade ring } \\
\text { s:slope angle }\end{array}$ \\
\hline
\end{tabular}

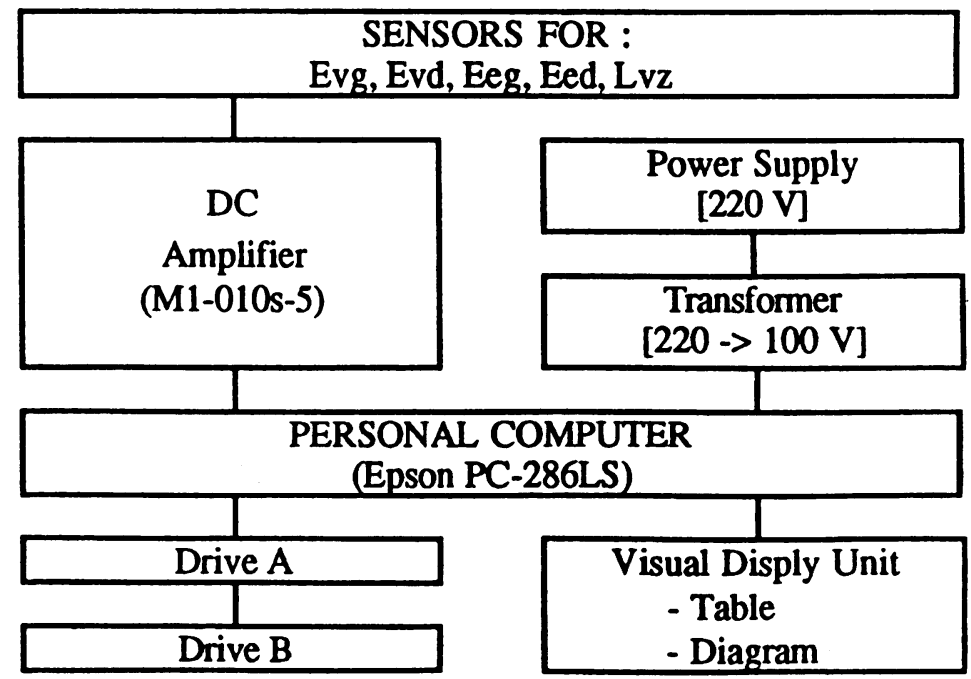

Fig. 2 Measurement system 